\title{
Soyo-san reduces depressive-like behavior and proinflammatory cytokines in ovariectomized female rats
}

\author{
Hyun-Jung Park ${ }^{1 \dagger}$, Hyun-Soo Shim ${ }^{1,2 \dagger}$, Sun Yong Chung ${ }^{3}$, Tae Hee Lee ${ }^{4}$ and Insop Shim ${ }^{1 *}$
}

\begin{abstract}
Background: Soyo-san is a traditional oriental medicinal formula, a mixture of 9 crude drugs, and it has been clinically used for treating mild depressive disorders. The role of pro- and anti-inflammatory cytokines in psychiatric disorders has been the focus of great research attention in recent years. In the present study, we detected the antidepressant effect of soyo-san in the ovariectomized and repeated stressed female rats.

Methods: This study was designed to evaluate the antidepressant-like effect of soyo-san on the forced swimming test (FST). The rats were randomly divided into the following groups: the nonoperated and nonstressed group (non-op), the nonoperated and stressed group (non-op $+S T)$, the ovariectomized and stress group $(\mathrm{OVX})$ and sham operated and stressed group (sham), the ovariectomized and stressed group (OVX $+\mathrm{ST})$, the ovariectomized, stressed and soyo-san $100 \mathrm{mg} / \mathrm{kg}$ treated group (SOY100) and the ovariectomized, stressed and soyo-san $400 \mathrm{mg} / \mathrm{kg}$ treated group (SOY400). The rats were exposed to immobilization stress (IMO) for 14day ( $2 \mathrm{~h} / 14$ day), and soyo-san (100 mg/kg and $400 \mathrm{mg} / \mathrm{kg}$ ) was administrated during the same time. In the same animals, the levels of corticosterone and interleukin-1-beta (IL-1 $\beta$ ) were examined in the serum. Also, the change of IL-1 $\beta$ expression in brain regions was examined after behavior test.
\end{abstract}

Results: In the FST, the lower dose $(100 \mathrm{mg} / \mathrm{kg}$ ) of extract was effective in reducing immobility, along with an increase in swimming time. The serum levels of corticosterone and IL-1 $\beta$ in the SOY groups were significantly lower than those in the control group. In the brain, the expression of IL-1 $\beta$ positive neurons in the control group were significantly increased in the paraventricular nucleus (PVN) and hippocampus compared to the non-op. However, soyo-san groups significantly reduced the IL-1 $\beta$-ir neurons in the PVN and hippocampal regions compared to the control.

Conclusion: The present results demonstrated that soyo-san effectively reduced behavioral and patho-physiological depression-like responses. Trial registration: Our results suggest that soyo-san may be useful for immune regulator in repeated stress-induced ovariectomized female rats.

\section{Background}

Postmenopausal women often suffer from symptoms called postmenopausal syndrome. These symptoms consist of hot flush and mental symptoms such as depression, irritation and insomnia [1,2]. Menopause is associated with a rapid decline in circulating sexual hormones and results in menopausal syndrome, including hot flushes, osteoporosis and affective disorders, for example, anxiety and depression. Those symptoms are known to be related to the decrease

\footnotetext{
* Correspondence: ishim@khu.ac.kr

${ }^{\dagger}$ Equal contributors

'Acupuncture and Meridian Science Research Center (AMSRC), Kyung Hee University, 1 Hoegi-dong, Dongdaemun-gu, Seoul 130-701, Republic of Korea Full list of author information is available at the end of the article
}

of the serum $17 \beta$-estradiol $\left(\mathrm{E}_{2}\right)$ level $[2,3]$. The decrease of $E_{2}$ has an influence on regulating the production of corticosterone and changing the behavioral response under the stress condition.

Repeated immobilization stress or unpredictable footshock elicit sickness behaviors, which may reflect part of a constellation of adaptive changes elicited by macrophage derived cytokines, such interleukin- $1 \beta$ and interferon- $\gamma$ $[4,5]$. These cytokines may directly or indirectly affect CNS processes [6] and thus may have implications for psychopathology, including depressive illness if the increased level of pro-inflammatory cytokines is involved in the etiology of depression, it may be expected that antidepressants should have a restoring immunoregulatory effect. Pharmacological

\section{Biomed Central}


studies with adrenaline transporter (NET) inhibitors such as desipramine $[7,8]$ have indicated the involvement of noradrenergic system underlying the effects of antidepressants on immune activity.

We already reported that the antidepressant effects of soyo-san on immobilization stress in ovariectomized female rats. The treatment with soyo-san caused significant reversals of the stress-induced deficits in learning and memory on a spatial memory task, and it also produced an anxiolytic-like effect on the EPM, and increased the ChAT and AchE reactivities. The serum level of corticosterone in the soyosan treated group was significantly lower than that in the control group. In this study, we aimed to investigate whether administration of soyo-san could modulate depressive-like behavior and production of pro-inflammatory cytokines. To achieve this goal, soyosan's antidepressant effect was tested via a forced swimming test (FST); moreover, the influence of soyo-san in producing of IL-1 $\beta$ was further assessed in the serum and brain regions using the ELISA and immunohistochemistry.

\section{Methods}

\section{Subjects and stress procedure}

Sprague Dawley female rats at the age of 3 months (Orient, Inc. Korea) were used for the study. The rats were housed under a controlled temperature $\left(22-24^{\circ} \mathrm{C}\right)$ with a $12 \mathrm{~h}$ light/ dark cycle. The lights were on from 8:00 to 20:00. Food and water were made available ad libitum. They were allowed at least 1 week to adapt to their environment before the experiments. The animal experiments were carried out in accordance with the Prevention of Cruelty to Animals Act 1986 and $\mathrm{NIH}$ guidance for the care and use of laboratory animals for experimental procedures, and all experiments in this study were approved by the Institutional Animal Care and Use Committee of Kyung Hee University (KHUAP(SE)-13-041).

The rats were randomly divided into the following groups: the nonoperated and nonstressed group (non$\mathrm{op})$, the nonoperated and stressed group (non-op + ST), the ovariectomized and stress group (OVX) and sham operated and stressed group (sham), the ovariectomized and stressed group $(\mathrm{OVX}+\mathrm{ST})$, the ovariectomized, stressed and soyo-san $100 \mathrm{mg} / \mathrm{kg}$ treated group (SOY100) and the ovariectomized, stressed and soyo-san $400 \mathrm{mg} / \mathrm{kg}$ treated group (SOY400). Using aseptic conditions, bilateral ovariectomy was performed under general anesthesia with pentobarbital sodium $(50 \mathrm{mg} / \mathrm{kg}$, i.p.). After postoperative recovery for 1 week, the ovariectomized rats were stressed daily. Stress was produced by forcing the animals into an immobilizer device (a disposable rodent restraint cone) for 2 hours (10:00-12:00 a.m.) for 2 weeks. The soyo-san group was orally administrated once daily for 2 weeks, and other groups were given sterile saline. Drug treatments began $30 \mathrm{~min}$ before the immobilization stress.

\section{Preparation of herbal extracts}

Soyo-san was purchased from an oriental drug store (Jungdo Inc. Seoul, Korea). The boucher specimens are deposited at the herbarium located in the College of Oriental Medicine, Kyung Hee University. The dried soyo-san samples $(720.58 \mathrm{~g}$, Table 1$)$ were immersed in a 10 -fold volume of distilled water, boiled at $80^{\circ} \mathrm{C}$ for $1 \mathrm{~h}$, and then the water extract was collected. The process was repeated once, and the extracts were combined and concentrated with a rotary evaporator and vacuum-dried to yield $6.6 \%(\mathrm{w} / \mathrm{w})$ of the extract.

\section{Forced swimming test}

From the $14^{\text {th }}$ day after the first immobilization, rats were placed in an FST, The time interval was $5 \mathrm{~min}$. The FST was originally described by Porsolt et al. [9] and now is the most widely used pharmacological model for assessing antidepressant activity [10]. The development of immobility when the rodents are placed in an inescapable cylinder of water reflects the cessation of persistent escape-directed behavior [11]. The apparatus consisted of a transparent Plexiglas cylinder $(50 \mathrm{~cm}$ high $\times 20 \mathrm{~cm}$ wide) filled to a $30 \mathrm{~cm}$ depth with water at room temperature. In the pre-test, rats were placed in the cylinder for $15 \mathrm{~min}$, $24 \mathrm{~h}$ prior to the 5-min swimming test. Soyo-san extract $(100,400 \mathrm{mg} / \mathrm{kg}$ ) or saline was administrated p.o. three times: immediately after the initial $15 \mathrm{~min}$ pre-test, 5 and $1 \mathrm{~h}$ prior to the swimming test. During the 5-min swimming test, the following behavioral responses were recorded by a trained observer: Climbing behavior, which is defined as upward-directed movements of the forepaws along the side of the swim chamber. Swimming behavior, defined as movement throughout the swim chamber, which included crossing into another quadrant. Immobility was considered when the rat made no further attempts to escape except the movement necessary to keep its head above the water. Increases in active responses, such as climbing or swimming, and reduction in immobility, are

\section{Table 1 Composition of soyo-san}

\begin{tabular}{lc}
\hline Medicinal plant & Amount (g) \\
\hline Paeoliae Radix Alba & 4.0 \\
\hline Atractylodis Macrocephalae Phizoma & 4.0 \\
\hline Angelicae Gigantis Radix & 4.0 \\
\hline Poria & 4.0 \\
\hline Liriopis Tuber & 4.0 \\
\hline Bupleuri Radix & 4.0 \\
\hline Menthae Herba & 2.0 \\
\hline Glycyrrhizae Radix & 2.0 \\
\hline Zingiberi Rhizoma Recens & 6.0 \\
\hline Total & 34.0 \\
\hline
\end{tabular}


considered as behavioral profiles consistent with an antidepressant-like action [10].

\section{Corticosterone and cytokine measurements}

After the behavior test, blood sample was taken in heart and then plasma separated from the blood was used to estimate the cytokine levels. Enzyme-linked immunosorbent assay (ELISA) was performed using Quantikine ELISA development system according to the manufacturer's instructions ( $\mathrm{R}$ \& D Systems, Minneapolis, MN, USA). Briefly, polystyrene microtiter plates (NUNC, U16 Maxisorp type, Roskilde, Denmark) were coated with monoclonal antibody (anti-rat IL-1 $\beta$ and corticosterone) obtained from rat ( $\mathrm{R} \& \mathrm{D}$ Systems) and incubated at $4^{\circ} \mathrm{C}$ overnight. The following day, the plates were blocked and then incubated for $2 \mathrm{~h}$ with plasma. This was followed by the addition of corresponding biotinylated detection antibody obtained from rat (R \& D Systems) and incubated for $2 \mathrm{~h}$. Streptavidin horseradish peroxidase ( $\mathrm{R} \& \mathrm{D}$ Systems) and, then, tetramethylbenzidine substrate (Bangalore Genei, Bangalore, India) treatment followed this incubation. The reaction was stopped using $2 \mathrm{~N}$ sulfuric acid, and optical density reading was taken at $450 \mathrm{~nm}$ (ELISA reader: Organon Teknika Microwell system, Reader 230 s, Eppelheim, Germany). All the experiments were conducted in duplicate. A standard curve was obtained based on the standards provided by the manufacturer. The results were expressed as concentration of cytokines (in $\mathrm{pg} / \mathrm{ml}$ ) read from the standard curve.

\section{IL-1 $\beta$ immunohistochemistry}

After the behavioral testing was completed, all of the animals were deeply anesthetized with sodium pentobarbital (80 $\mathrm{mg} / \mathrm{kg}$, i.p.) also, blood sample was taken in heart and then they were perfused through the ascending aorta with normal saline $(0.9 \%)$, followed by $800 \mathrm{ml}$ of $4 \%$ paraformaldehyde in $0.1 \mathrm{M}$ phosphate buffer saline (PBS). The brains were removed, postfixed overnight and cryoprotected in $20 \%$ sucrose in $0.1 \mathrm{M} \mathrm{PBS}$ at $4^{\circ} \mathrm{C}$. The brains were cut by cryostat sectioning into $30 \mu \mathrm{m}$ coronal sections at the level of the hippocampus, and these slices were processed histochemically as free-floating sections.

The brain sections were washed in PBS containing $0.3 \%$ Triton X-100. The primary goat polyclonal antibodies against the following specific antigen were used: Intetleukin-1-beta (IL-1 $\beta$, concentration 1:100; R\&D Systems, Minneapolis, USA). The primary antibodies were diluted with blocking solution (10\% fetal bovine serum in PBS, $\mathrm{pH}=7.4$ ) and the tissues were incubated for $72 \mathrm{~h}$ at $4^{\circ} \mathrm{C}$ with constant agitation. Following rinsing in PBS, the sections were incubated for $2 \mathrm{~h}$ at room temperature in biotinylated goat anti-serum (Vector Laboratories, Burlingame, CA) that was diluted 100:1 in PBST containing $2 \%$ normal rabbit serum. The sections were placed in Vectastain Elite $\mathrm{ABC}$ reagent (Vector Laboratories, Burlingame, $\mathrm{CA}$ ) for $2 \mathrm{~h}$ at room temperature. Following a further rinsing in PBS, the tissue was developed using diaminobenzidine chromogen with nickel intensification. The sections were mounted on gelatine-coated slides, airdried and coverslipped for microscopic observation. For measuring the cells, a microrectangular grid $(200 \times 200 u m)$ was placed according to the atlas of Paxinos and Watson under the light microscope ( $\times 100$ magnification) [12].

\section{Data analysis}

Statistical comparisons were done for the behavioral, histochemical and immunological studies using the oneway ANOVA, respectively, and Tukey post hoc was done. All of the results were presented as means \pm S.E.M., and we used SPSS 15.0 for Windows for analysis of the statistics. The significance level was set at $p<0.05$.

\section{Results}

\section{Forced swimming test}

The effect of the soyo-san on active behaviors in the FST of rats are shown in Figure 1. ANOVA revealed effects of the treatment of soyo-san on immobility, $\mathrm{F}_{3,30}=5.214, P<$ 0.05; swimming behavior, $F_{3,30}=0.328$; and climbing behavior, $F_{3,30}=0.150$. Post hoc analysis demonstrated that soyo-san treatment groups significantly shortened the immobility time in comparison to control values $(P<0.05)$. This effect was accompanied by increases in swimming behavior, after 100 and $400 \mathrm{mg} / \mathrm{kg}$. These results indicated that higher doses $(400 \mathrm{mg} / \mathrm{kg})$ were more effective than soyo-san $100 \mathrm{mg}$ in reducing immobility time.

\section{ELISA}

1) Corticosterone (CORT)

Figure 2A shows that the serum levels of CORT were significantly different in comparisons among the groups $\left(\mathrm{F}_{3,30}=4.093, P<0.05\right)$. The serum levels of CORT were $195.6 \pm 15.4,226.3 \pm 42.4$, $179.1 \pm 40.3$ and $99.1 \pm 19.6(\mathrm{ng} / \mathrm{ml})$ in the non-op, OVX+ST, SOY100 and SOY400 groups, respectively. The LSD test results indicated a significantly increased the serum levels of CORT in the non-op group compared to the OVX+ST group $(P<0.05)$. After treatment of soyo-san, the serum levels of CORT were significantly decreased in the SOY100 group $(P<0.05)$ and SOY400 group $(P<0.01)$ compared to the $\mathrm{OVX}+\mathrm{ST}$ group.

2) IL-1 $\beta$

Figure $2 \mathrm{~B}$. shows that the serum levels of IL-1 $\beta$ were significantly different in comparisons among the groups $\left(\mathrm{F}_{3,30}=4.1, P<0.05\right)$. The serum levels of IL- $1 \beta$ were $15.6 \pm 4.0,30.6 \pm 3.3,19.3 \pm 3.0$ and $18.7 \pm 2.4(\mathrm{pg} / \mathrm{ml})$ in the non-op, OVX+ST, 

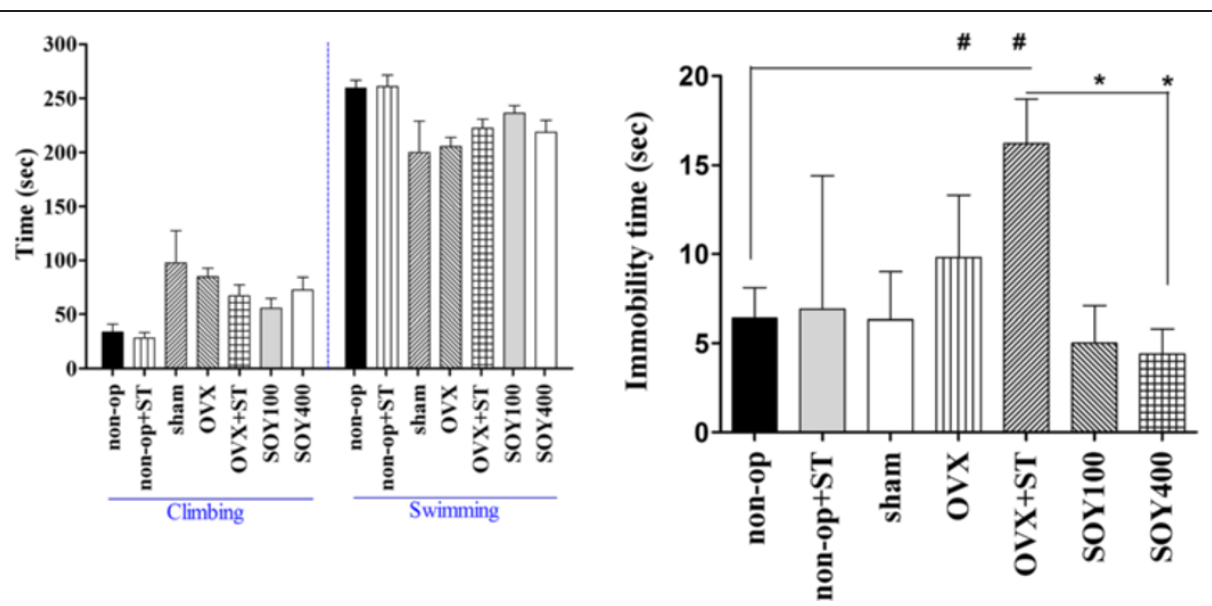

Figure 1 The effects of soyo-san extract on CORT (A), IL-1 $\beta$ (B) levels in the serum. The results of ELISA were analyzed by performing separate one-way ANOVA among the groups. Each value represents the mean \pm S.E.M. ${ }^{*} P<0.05,{ }^{* *} P<0.01$ compared to OVX + ST. \#P<0.05, $\# \# P<0.01$ compared to non-op.

SOY100 and SOY400 groups, respectively. The LSD test results indicated a significantly increased the serum levels of IL-1 $\beta$ in the non-op group compared to the stressed group $(P<0.01)$. After treatment of soyo-san, the serum levels of IL-1 $\beta$ were significantly decreased to $33.0 \%$ of the stress in the soyo-san groups $(P<0.05)$.

\section{IL-1 $\beta$ Immunohitochemistry}

The results of determining the IL- $1 \beta$ immunoreative cells per section from different hippocampal formations and paraventricular nucleus are shown in Figures 3 and 4 . The number of IL-1 $\beta$ neurons in the CA1 area was $10.1 \pm 0.6$ in the non-op group, $3.9 \pm 0.6$ in the OVX group, $3.0 \pm 0.3$ in the SOY100 group and $6.0 \pm 0.4$ in the SOY400 group $\left[\mathrm{F}_{3,20}=11.7, P<0.001 ; 3 \mathrm{~A}-\mathrm{I}\right]$. IL-1 $\beta$ immunoreactive cells in the CA3 area were $18.4 \pm 0.6$ in the non-op group, $13.7 \pm$ 0.8 in the OVX group, $12.9 \pm 0.3$ in the SOY100 group and $15.7 \pm 0.5$ in the SOY400 group $\left[\mathrm{F}_{3,20}=6.0, P<0.01\right]$.

Also, the number of IL-1 $\beta$ positive neurons was significantly increased to $121.7 \%$ of the OVX in the non-op group $(P<0.01)$. The number of IL- $1 \beta$ neurons in the PVN area was $7.2 \pm 1.5$ in the non-op group, $27.3 \pm 1.3$ in the OVX group, $13.5 \pm 1.8$ in the SOY100 group and $11.8 \pm 1.5$ in the SOY400 group $\left[\mathrm{F}_{3,20}=32.4, P<0.001 ; 4 \mathrm{~A}-\mathrm{E}\right]$.

\section{Discussion}

The present study demonstrated that the administration of soyo-san reduced the depressive behavior and proinflammatory cytokine expression. These results suggest that repeated immobilization stress in the ovariectomized female rats is an immune challenge capable of inducing
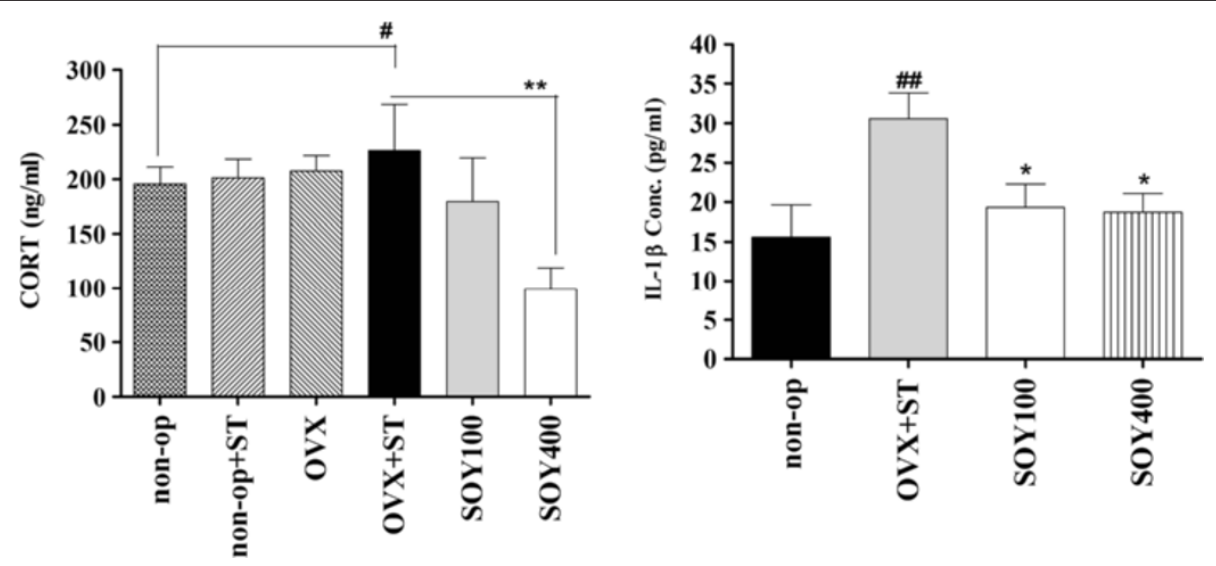

Figure 2 The climbing and swimming time (A) and the immobility time (B) of rats on the forced swimming. Data represent means \pm S.E. M. of the duration of climbing, swimming and immobility during the 5-min test session. The results of FST were analyzed by performing separate one-way ANOVA of mean counts among the groups. Each value represents the mean \pm S.E.M. ${ }^{*} P<0.05$ compared to OVX+ST. \#P< 0.05 compared to non-op. 

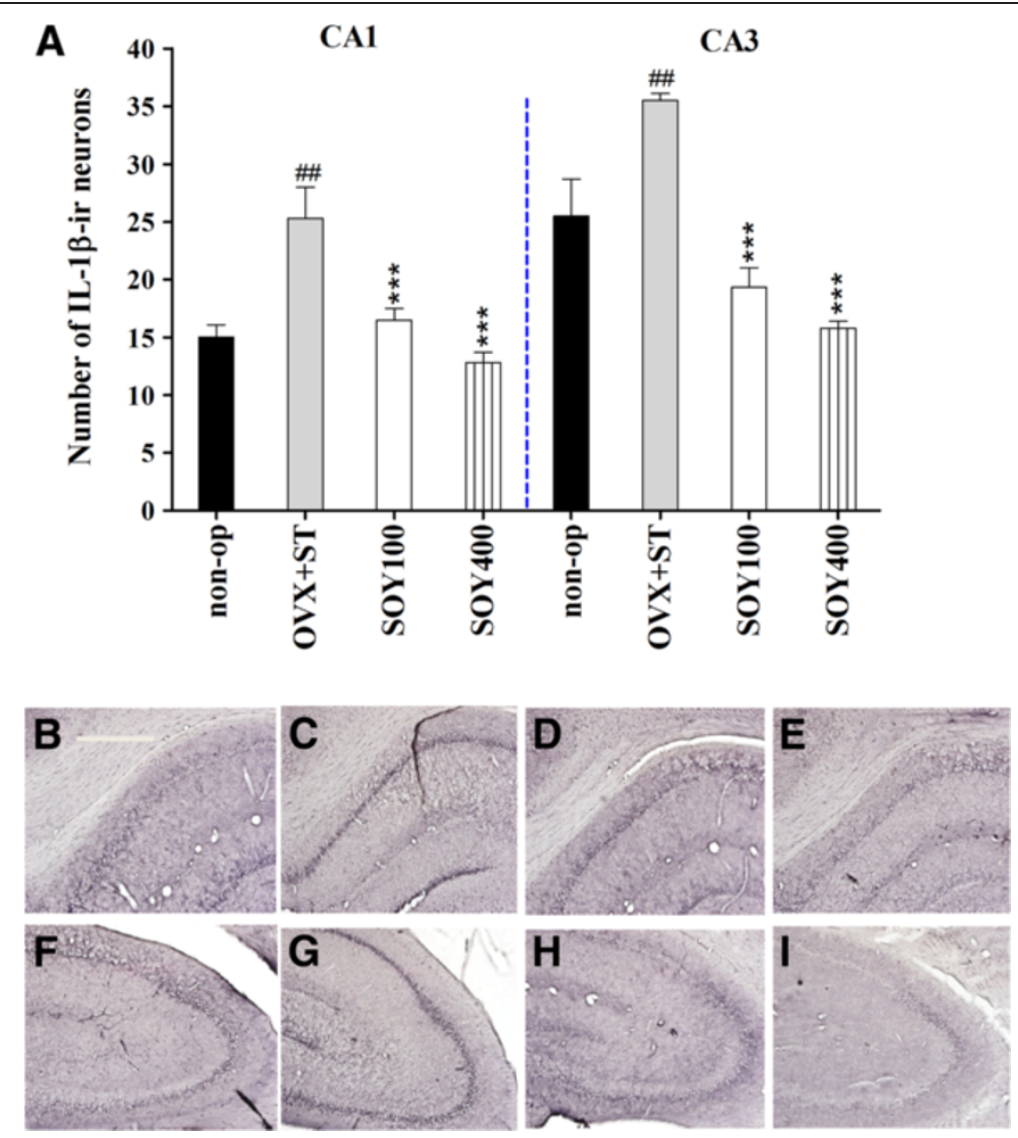

Figure 3 The effect of soyo-san extract on quantities of IL-1 $\beta$ immunostained nuclei expression in the hippocampal regions of the experimental groups after forced swimming test. (A) The results of IL-1 $\beta$-reactivity were analyzed by performing separate one-way ANOVA of neurons among the groups. Each value represents the mean \pm S.E.M. ${ }^{* * *} P<0.001$ compared to OVX+ST. \#\#P<0.01 compared to non-op. B-I: Representative photographs of IL-1ß-immunostained brain sections. Scale bars, 200 um. non-op (B,F), OVX+ST (C,G), SOY 100 (D,H) and SOY $400(E, I)$.

depressive-like behavior, promoting exaggerated glucocorticoid responses to stress, and changing cytokine transcription in the serum and the brain.

Depression is defined clinically as a pathological complex of psychological, neuroendocrine and somatic symptoms that cannot be reproduced in animals. To date, few models are commonly used for screening antidepressant effects or studying the mechanisms of action of these molecules. The forced swimming test (FST) was discussed the main parameters that influence the sensitivity, specificity and reliability of this model. Porsolt et al. (1977) [13] described "a new behavioural method for inducing a depressed state". The idea arose out of some learning experiments they were doing with rats in a water maze. Most rats were finding the exit within $10 \mathrm{~min}$ but they noticed that other rats ceased struggling altogether and remained floating passively [9]. The duration of immobility occurring in each minute was scored. A wide variety of antidepressants, and compounds with potential antidepressant activity, reduce the duration of immobility in the forced swimming test [14-16]. The present study confirms the previously reported antidepressant like effect of soyo-san. The reduction in immobility induced by soyo-san was accompanied by increased swimming, while that of soyo-san occurred with an increase in climbing behavior. The behavioral profiles observed in the present study with soyo-san, in ovariectomized female rats, are similar to those reported by other authors in male rats [17-21]. Hence, the finding of Chen et al. [22] can also be extended to repeated stress induced depression animal model. In a Previous study, we also demonstrated that Bupleuri radix, one of the most important constituents of soyo saan, caused a significant anti-immobility effect on the FST and reversed the CMS-induced reduction of sucrose consumption [23]. In agreement with these findings, the previous studies on major depressive disorder have reported the elevation of IL-1 $\beta$ production during a depressive state [24]. This study also showed the repeated immobilization stress induced a broad spectrum of behavioral changes that might be regarded as depression-like symptoms, including reduction of preferences for sucrose solution, inhibition of locomotor activities, and induction of learned helplessness behavior. 

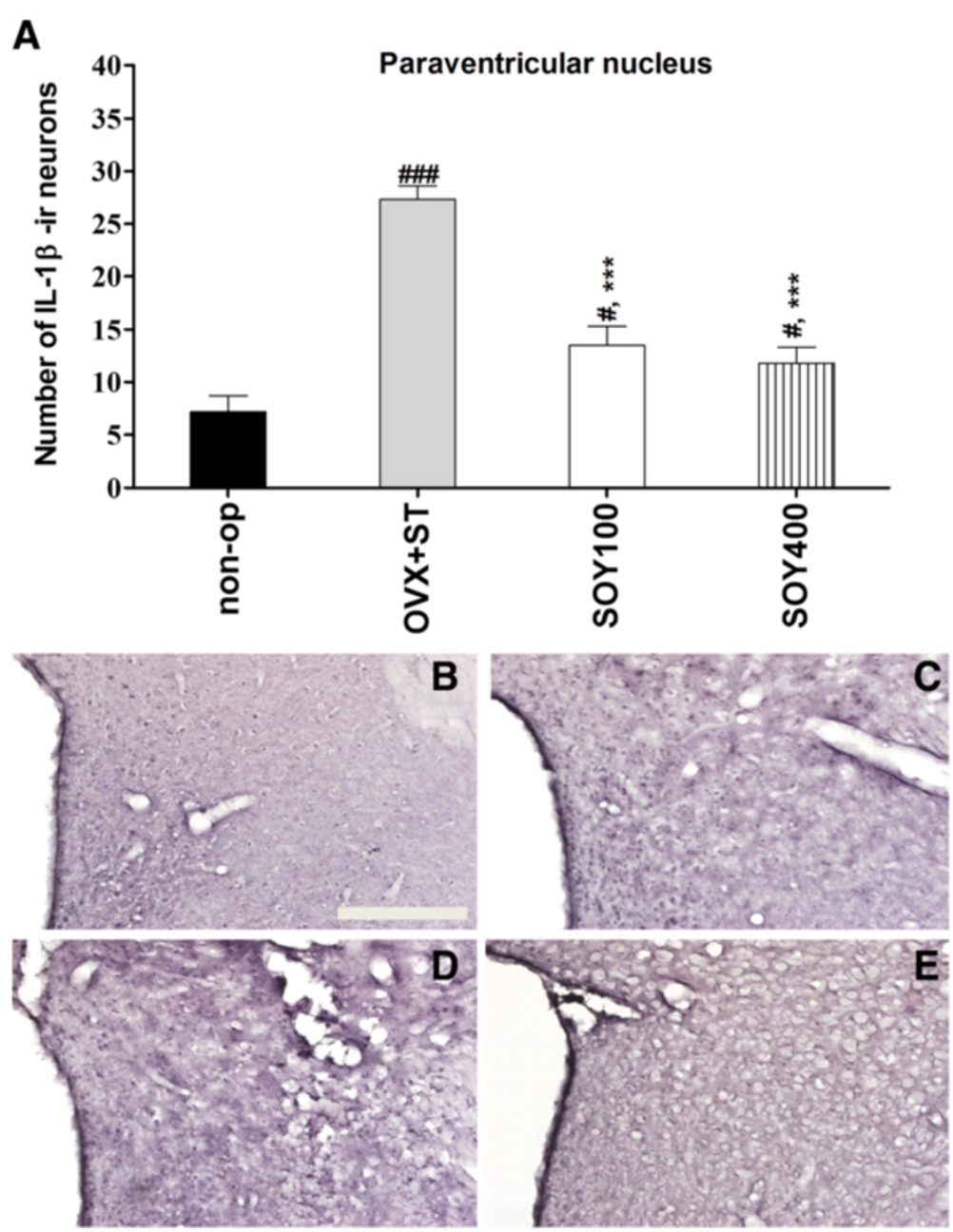

Figure 4 The effect of soyo-san extract on quantities of IL-1 $\beta$ immunostained nuclei expression in the paraventricular regions of the experimental groups after forced swimming test. (A) The results of IL-1 $\beta$-reactivity were analyzed by performing separate one-way ANOVA of neurons among the groups. Each value represents the mean \pm S.E.M. ${ }^{* *} P<0.001$ compared to non-op. \#P<0.05, \#\#\#P<0.001 compared to non-op. B-E Representative photographs of IL-1 $\beta$-immunostained brain sections. Scale bars, 200um. non-op (B), OVX +ST, SOY 100 (D) and SOY 400 (E).

Several lines of evidence have indicated that menopause is associated with increased susceptibility to neurological disorders [25], also the mechanisms were elucidated [25-27]. Previous studies revealed a substantial involvement of endogenous estrogen in neuroinflammatory processes and provide novel mechanisms for hormone action in the brain [25-27]. Another study reported that the estrogen replacement therapy (ERT) was related to exacerbate the memory impairment induced by the chronic neuroinflammation associated with Alzheimer's disease [27]. In this study, our aim is to investigate whether OVX animals are more vulnerable to the inflammatory and behavioral effects of chronic stress. Many studies proved that the repeated stress accelerated expression of pro-inflammatory cytokines in the brain [28-30]. Pro-inflammatory cytokines play a key role in determining the nature and strength of immune responses [31]. Previous studies have demonstrated that the induction of pro-inflammatory cytokines activated under stress condition. Stress (physical, psychological or both of them) can increase an inflammatory responses. The relationship between stressful events and the onset of inflammatory related diseases (injury, ischemia, Alzheimer's disease) is well documented [32]. Stress response is very similar to the inflammatory process generated in an organism when invaded by certain microorganisms or after injury or tissue damage as oxidative stress. In rodents, unavoidable physical stresses are the most extensively used: immobilization, exposure to extreme temperatures, fasting, immersion or electric foot shock. Various studies have provided inputs on the molecular signaling that links stress-induced neuro-endocrine-immune interactions, suggesting a bi-directional crosstalk which is based on the secretion of cytokines, glucocorticoids, neurotransmitters and neuropeptides [33]. The previous study proved that 
the sex difference in novelty exposure observed in the form of a greater hypothalamic-pituitary-adrenal (HPA) axis response in female ICR mice is controlled by ovaryderived factors in adults [34]. Ovariectomy expresses high levels of adrenal steroid receptors and is susceptible especially to damage as a result of stress [35]. Women have a higher incidence of some stress-related disorders, such as depression, while men are generally at a greater risk for cardiovascular diseases, such as myocardial infarction and hypertension, than age-matched, premenopausal women [36]. The higher incidence and severity of depression are associated with the presence or absence of ovarian hormones [37]. The present study showed hyperactivity of the pro-inflammatory cytokine after stress. Pro-inflammatory cytokine's overproduction could be integrated in the inflammatory response system, which is activated during depression, and this is consistent with the shift of the pro-/ anti-inflammatory cytokine mechanism. Buchanan et al. reported that psychological stress increases the brain levels

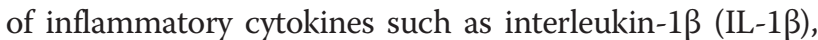
IL-6 and tumor necrosis factor $\alpha$ (TNF- $\alpha)$ [38]. Zili et al. detected depression like behavior in a rat animal model which was induced inflammation in the spleen and brain by chronic mild stress (CMS) [39]. In the present study, we observed that the expression of IL-1 $\beta$ immunoreactive cells was up-regulated in paraventricular nucleus (PVN), motor trigeminal nucleus (MTN), hippocampus after repeated immobilization stress. The results from depressionlike animal model were consistent with previous reports, which indicated that life events and depressive symptoms are associated with the rise of central cytokine such as IL-1 $\beta$ in human MDD patents [40-47] and stress-treated animals [48-50]. However, the administration of soyo-san significantly reduced the expression of IL-1 $\beta$. Menthae herbam, a component of soyo-san modified prescription on plasma metabolomics of rats with chronic immobilization stress [51]. Angelicae gigantis radix, a component of soyo-san, exhibited an anti-inflammatory effect in vitro, in vivo and inhibits the stress-induced pathophysiological changes in the central nervous system [52]. Also, paeoniflorin has neuroprotective effect and inhibition of neuroinflammation [53].

\section{Conclusion}

In conclusion, soyo-san decreased the immobility time in FST. Soyo-san also inhibited repeated stress induced IL-1 $\beta$ production in hippocampus and PVN. These results have shown that IL-1 $\beta$, a pro-inflammatory cytokine, is an important molecule in the modulation of depressive-like behavior. This finding calls for a reappraisal of the "cytokine hypothesis of depression". Further studies are encouraged to analyze the therapeutic effect of different levels of estrogenic compounds, which lack feminine proprieties, on different setting of immune diseases.
Competing interests

The author declares that they have no competing interests.

\section{Authors' contributions}

$\mathrm{HS}$ and $\mathrm{HJ}$ conducted the animal experiment and analyzed the data. IS, HJ, SY and TH participated in design of the study and preparation of the manuscript. All the authors read and approved the final manuscript.

\section{Acknowledgement}

This research was supported by Original Technology Research Program for Brain Science through the National Research Foundation of Korea (NRF) funded by the Ministry of Education, Science and Technology (20110030091 and 2013R1A1A2011292). Is was supported by the 2013 research leave program grant from Kyung Hee University.

\section{Author details}

${ }^{1}$ Acupuncture and Meridian Science Research Center (AMSRC), Kyung Hee University, 1 Hoegi-dong, Dongdaemun-gu, Seoul 130-701, Republic of Korea. 2Department of Oriental Medical Science, College of Oriental Medicine, Graduate School, Kyung Hee University, Seoul 130-701, Korea. ${ }^{3}$ Department of Oriental Neuropsychiatry, Kyung Hee University Korean Medicine Hospital at Gangdong, Seoul 130-701, Korea. ${ }^{4}$ Department of Formulae Pharmacology, School of Korean Medicine, Graduate School of Gachon University,

Seongnam, Gyeonggi-do 461-701, Korea.

Received: 15 January 2013 Accepted: 2 January 2014

Published: 21 January 2014

\section{References}

1. Dhabhar FS: Acute stress enhances while chronic stress suppresses skin immunity. The role of stress hormones and leukocyte trafficking. Ann N Y Acad Sci 2000, 917:876-893.

2. Session DR, Kelly AC, Jewelewicz R: Current concepts in estrogen replacement therapy in the menopause. Fertil Steril 1993, 59(2):277-284.

3. Imai A, Matsunami $K$, Takagi $H$, Ichigo S: New generation nonhormonal management for hot flashes. Gynecol Endocrinol 2013, 29(1):63-66.

4. Brebner K, Hayley S, Zacharko R, Merali Z, Anisman H: Synergistic effects of interleukin-1 beta, interleukin-6, and tumor necrosis factor-alpha: central monoamine, corticosterone, and behavioral variations.

Neuropsychopharmacology 2000, 22(6):566-580.

5. Kusnecov A, Sved A, Rabin BS: Immunologic effects of acute verses chronic stress in animals. In Psychoneuroummunology. Edited by Ader R Felten DL, Cohen N. New York: Academic press; 2001:265-278.

6. Anisman $\mathrm{H}$, Merali Z: Anhedonic and anxiogenic effects of cytokine exposure. Adv Exp Med Biol 1999, 461:199-233.

7. Kubera M, Basta-Kaim A, Holan V, Simbirtsev A, Roman A, Pigareva N, Prokopieva E, Sham J: Effect of mild chronic stress, as a model of depression, on the immunoreactivity of C57BL/6 mice. Int J Immunopharmacol 1998, 20(12):781-789.

8. Szelenyi J, Selmeczy Z: Immunomodulatory effect of antidepressants Curr Opin Pharmacol 2002, 2(4):428-432.

9. Porsolt RD, Le Pichon M, Jalfre M: Depression: a new animal model sensitive to antidepressant treatments. Nature 1977, 266(5604):730-732.

10. Cryan JF, Markou A, Lucki I: Assessing antidepressant activity in rodents: recent developments and future needs. Trends Pharmacol Sci 2002, 23(5):238-245.

11. Lucki I: The forced swimming test as a model for core and component behavioral effects of antidepressant drugs. Behav Pharmacol 1997, 8(6-7):523-532.

12. Paxinos G, Watson C, Pennisi M, Topple A: Bregma, lambda and the interaural midpoint in stereotaxic surgery with rats of different sex, strain and weight. J Neurosci Methods 1985, 13(2):139-143.

13. Porsolt RD, Martin P, Lenegre A, Fromage S, Drieu K: Effects of an extract of Ginkgo Biloba (EGB 761) on "learned helplessness" and other models of stress in rodents. Pharmacol Biochem Behav 1990, 36(4):963-971.

14. Koe BK, Weissman A, Welch WM, Browne RG: Sertraline, 1S,4S-N-methyl-4(3,4-dichlorophenyl)-1,2,3,4-tetrahydro-1-naphthylamine, a new uptake inhibitor with selectivity for serotonin. J Pharmacol Exp Ther 1983, 226(3):686-700 
15. Panconi E, Roux J, Altenbaumer M, Hampe S, Porsolt RD: MK-801 and enantiomers: potential antidepressants or false positives in classical screening models? Pharmacol Biochem Behav 1993, 46(1):15-20.

16. Porsolt RD, Lenegre A, Avril I, Lancrenon S, Steru L, Doumont G: Psychopharmacological profile of the new cognition enhancing agent exifone in the mouse. Arzneimittelforschung 1987, 37(4):388-393.

17. Mizowaki M, Toriizuka K, Hanawa T: Anxiolytic effect of Kami-Shoyo-San (TJ-24) in mice: possible mediation of neurosteroid synthesis. Life Sci 2001, 69(18):2167-2177.

18. Qu Y, Gan HQ, Mei QB, Liu L: Study on the effect of Jia-Wei-Xiao-Yao-San decoction on patients with functional dyspepsia. Phytother Res 2010, 24(2):245-248.

19. Yang YH, Chen PC, Wang JD, Lee CH, Lai JN: Prescription pattern of traditional Chinese medicine for climacteric women in Taiwan. Climacteric 2009, 12(6):541-547.

20. Yin SH, Wang CC, Cheng TJ, Chang CY, Lin KC, Kan WC, Wang HY, Kao WM, Kuo YL, Chen JC, et al: Room-temperature super-extraction system (RTSES) optimizes the anxiolytic- and antidepressant-like behavioural effects of traditional Xiao-Yao-San in mice. Chin Med 2012, 7(1):24.

21. Zhang Y, Han M, Liu Z, Wang J, He Q, Liu J: Chinese herbal formula xiao yao san for treatment of depression: a systematic review of randomized controlled trials. Evid Based Complement Altern Med 2012, 2012:931636.

22. Chen JX, Li W, Zhao X, Yang JX: Effects of the Chinese traditional prescription Xiaoyaosan decoction on chronic immobilization stressinduced changes in behavior and brain BDNF, TrkB, and NT-3 in rats. Cell Mol Neurobiol 2008, 28(5):745-755.

23. Bekris S, Antoniou K, Daskas S, Papadopoulou-Daifoti Z: Behavioural and neurochemical effects induced by chronic mild stress applied to two different rat strains. Behav Brain Res 2005, 161(1):45-59.

24. Buchanan JB, Sparkman NL, Chen J, Johnson RW: Cognitive and neuroinflammatory consequences of mild repeated stress are exacerbated in aged mice. Psychoneuroendocrinology 2008, 33(6):755-765.

25. Vegeto E, Belcredito S, Ghisletti S, Meda C, Etteri S, Maggi A: The endogenous estrogen status regulates microglia reactivity in animal models of neuroinflammation. Endocrinology 2006, 147(5):2263-2272.

26. Benedusi V, Meda C, Della Torre S, Monteleone G, Vegeto E, Maggi A: A lack of ovarian function increases neuroinflammation in aged mice. Endocrinology 2012, 153(6):2777-2788.

27. Marriott LK, Hauss-Wegrzyniak B, Benton RS, Vraniak PD, Wenk GL: Long-term estrogen therapy worsens the behavioral and neuropathological consequences of chronic brain inflammation. Behav Neurosci 2002 116(5):902-911.

28. Ambarish V, Chandrashekara S, Suresh KP: Moderate regular exercises reduce inflammatory response for physical stress. Indian J Physiol Pharmacol 2012, 56(1):7-14

29. Golovatscka V, Ennes H, Mayer EA, Bradesi S: Chronic stress-induced changes in pro-inflammatory cytokines and spinal glia markers in the rat: a time course study. Neuroimmunomodulation 2012, 19(6):367-376.

30. Kim SJ, Lee H, Joung HY, Lee G, Lee HJ, Shin MK, Kim SH, Shim I, Bae H: T-bet deficient mice exhibit resistance to stress-induced development of depression-like behaviors. J Neuroimmunol 2011, 240-241:45-51.

31. Paul WE, Seder RA: Lymphocyte responses and cytokines. Cell 1994, 76(2):241-251

32. Baum A, Posluszny DM: Health psychology: mapping biobehavioral contributions to health and illness. Annu Rev Psychol 1999, 50:137-163.

33. Sternberg EM: Neural regulation of innate immunity: a coordinated nonspecific host response to pathogens. Nat Rev Immunol 2006 6(4):318-328.

34. Aoki M, Shimozuru M, Kikusui T, Takeuchi Y, Mori Y: Sex differences in behavioral and corticosterone responses to mild stressors in ICR mice are altered by ovariectomy in peripubertal period. Zoolog Sci 2010, 27(10):783-789.

35. Kellendonk C, Gass P, Kretz O, Schutz G, Tronche F: Corticosteroid receptors in the brain: gene targeting studies. Brain Res Bull 2002, 57(1):73-83

36. Reckelhoff JF: Gender differences in the regulation of blood pressure. Hypertension 2001, 37(5):1199-1208.

37. Shors TJ, Leuner B: Estrogen-mediated effects on depression and memory formation in females. J Affect Disord 2003, 74(1):85-96.

38. Buchanan R, Popowych Y, Dagenais C, Arsic N, Mutwiri GK, Potter AA, Babiuk LA, Griebel PJ, Wilson HL: Interferon-gamma and B-cell Activating
Factor (BAFF) promote bovine B cell activation independent of TLR9 and T-cell signaling. Vet Immunol Immunopathol 2012, 145(1-2):453-463.

39. You Z, Luo C, Zhang W, Chen Y, He J, Zhao Q, Zuo R, Wu Y: Pro- and antiinflammatory cytokines expression in rat's brain and spleen exposed to chronic mild stress: involvement in depression. Behav Brain Res 2011 225(1):135-141.

40. Baune BT, Dannlowski U, Domschke K, Janssen DG, Jordan MA, Ohrmann P, Bauer J, Biros E, Arolt V, Kugel H, et al: The interleukin 1 beta (IL1B) gene is associated with failure to achieve remission and impaired emotion processing in major depression. Biol Psychiatry 2010, 67(6):543-549.

41. Einvik G, Vistnes M, Hrubos-Strom H, Randby A, Namtvedt SK, Nordhus $\mathbb{H}$, Somers VK, Dammen T, Omland T: Circulating cytokine concentrations are not associated with major depressive disorder in a community-based cohort. Gen Hosp Psychiatry 2012, 34(3):262-267.

42. Gabbay V, Klein RG, Alonso CM, Babb JS, Nishawala M, De Jesus G, Hirsch GS, Hottinger-Blanc PM, Gonzalez CJ: Immune system dysregulation in adolescent major depressive disorder. J Affect Disord 2009, 115(1-2):177-182

43. Hannestad J, DellaGioia N, Bloch M: The effect of antidepressant medication treatment on serum levels of inflammatory cytokines: a meta-analysis. Neuropsychopharmacology 2011, 36(12):2452-2459.

44. Hughes MM, Carballedo A, McLoughlin DM, Amico F, Harkin A, Frodl T, Connor TJ: Tryptophan depletion in depressed patients occurs independent of kynurenine pathway activation. Brain Behav Immun 2012, 26(6):979-987

45. Jazayeri S, Keshavarz SA, Tehrani-Doost M, Djalali M, Hosseini M, Amini H, Chamari M, Djazayery A: Effects of eicosapentaenoic acid and fluoxetine on plasma cortisol, serum interleukin-1 beta and interleukin- 6 concentrations in patients with major depressive disorder. Psychiatry Res 2010, 178(1):112-115.

46. Piletz JE, Halaris A, lqbal O, Hoppensteadt D, Fareed J, Zhu H, Sinacore J, Devane CL: Pro-inflammatory biomakers in depression: treatment with venlafaxine. World J Biol Psychiatry 2009, 10(4):313-323.

47. Rethorst CD, Toups MS, Greer TL, Nakonezny PA, Carmody TJ, Grannemann BD, Huebinger RM, Barber RC, Trivedi MH: Pro-inflammatory cytokines as predictors of antidepressant effects of exercise in major depressive disorder. Mol Psychiatry 2012, 18(10):1119-1124.

48. Hemshekhar M, Thushara RM, Jnaneshwari S, Devaraja S, Kemparaju K, Girish KS: Attenuation of adjuvant-induced arthritis by dietary sesamol via modulation of inflammatory mediators, extracellular matrix degrading enzymes and antioxidant status. Eur J Nutr 2012, 52(7):1787-1799.

49. Maslanik T, Tannura K, Mahaffey L, Loughridge AB, Benninson L, Ursell L, Greenwood BN, Knight R, Fleshner M: Commensal bacteria and MAMPs are necessary for stress-induced increases in IL-1beta and IL-18 but not IL-6, IL-10 or MCP-1. PLoS One 2012, 7(12):e50636.

50. Roy S, Metya SK, Sannigrahi S, Rahaman N, Ahmed F: Treatment with ferulic acid to rats with streptozotocin-induced diabetes: effects on oxidative stress, pro-inflammatory cytokines, and apoptosis in the pancreatic beta cell. Endocrine 2013, 44(2):369-379.

51. Luo HG, Chen JX, Zhang Q, Yue GX, Ding J, Zhang HT, Yan XZ, Zhao X Meng ZZ: Comparative study on effects of Xiaoyao Powder () and its modified prescription on plasma metabolomics of rats with chronic immobilization stress. Chin J Integr Med 2012, 19(8):610-615.

52. Sohn $Y$, Lee HS, Park HJ, Lee $H$, Lee $H$, Choi H, Jeong $C H, B u$, Jung HS: Angelicae Gigantis Radix regulates mast cell-mediated allergic inflammation in vivo and in vitro. Food Chem Toxicol 2012, 50(9):2987-2995

53. Liu $H Q$, Zhang WY, Luo XT, Ye Y, Zhu XZ: Paeoniflorin attenuates neuroinflammation and dopaminergic neurodegeneration in the MPTP model of Parkinson's disease by activation of adenosine $A 1$ receptor. Br J Pharmacol 2006, 148(3):314-325.

doi:10.1186/1472-6882-14-34

Cite this article as: Park et al:: Soyo-san reduces depressive-like behavior and proinflammatory cytokines in ovariectomized female rats. BMC Complementary and Alternative Medicine 2014 14:34. 